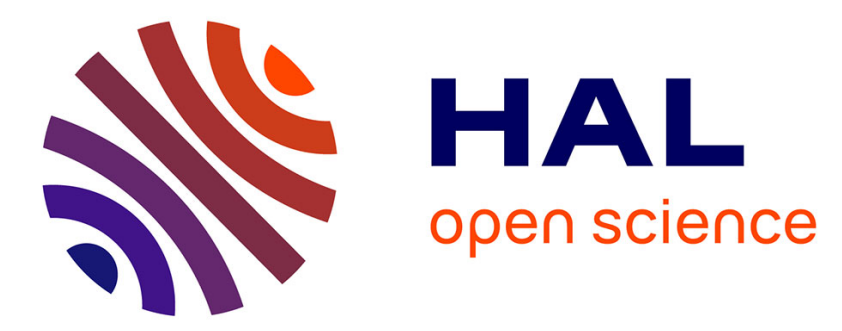

\title{
Passively mode-locked erbium-doped double-clad fiber laser operating at the 322nd harmonic
}

\author{
Foued Amrani, Adil Haboucha, Mohamed Salhi, Hervé Leblond, Andrey
}

Komarov, Philippe Grelu, François Sanchez

\section{- To cite this version:}

Foued Amrani, Adil Haboucha, Mohamed Salhi, Hervé Leblond, Andrey Komarov, et al.. Passively mode-locked erbium-doped double-clad fiber laser operating at the 322nd harmonic. Optics Letters, 2009, 34 (14), pp.2120-2122. 10.1364/OL.34.002120 . hal-03436305

\section{HAL Id: hal-03436305 \\ https://univ-angers.hal.science/hal-03436305}

Submitted on 19 Nov 2021

HAL is a multi-disciplinary open access archive for the deposit and dissemination of scientific research documents, whether they are published or not. The documents may come from teaching and research institutions in France or abroad, or from public or private research centers.
L'archive ouverte pluridisciplinaire HAL, est destinée au dépôt et à la diffusion de documents scientifiques de niveau recherche, publiés ou non, émanant des établissements d'enseignement et de recherche français ou étrangers, des laboratoires publics ou privés. 


\title{
Passively mode-locked erbium-doped double-clad fiber laser operating at the 322nd harmonic
}

\author{
F. Amrani, ${ }^{1}$ A. Haboucha, ${ }^{1}$ M. Salhi, ${ }^{1}$ H. Leblond, ${ }^{1}$ A. Komarov, ${ }^{2}$ Ph. Grelu, ${ }^{3}$ and F. Sanchez ${ }^{1, *}$ \\ ${ }^{1}$ Laboratoire POMA, FRE CNRS 2988, Université d'Angers, 2 Boulevard Lavoisier, 49000 Angers, France \\ ${ }^{2}$ Institute of Automation and Electrometry, Russian Academy of Sciences, Academician Koptyug Prospekt 1, \\ 630090 Novosibirsk, Russia \\ ${ }^{3}$ Institut Carnot de Bourgogne, UMR CNRS 5209, Université de Bourgogne, B.P. 47870, 21078 Dijon Cedex, France \\ *Corresponding author: francois.sanchez@univ-angers.fr
}

Received April 21, 2009; revised May 26, 2009; accepted May 28, 2009; posted June 8, 2009 (Doc. ID 110399); published July 7, 2009

We report passive mode locking of a soliton erbium-doped double-clad fiber laser operating at the 322nd harmonic of the fundamental cavity frequency. Repetition rates up to $3 \mathrm{GHz}$ have been obtained with pulses of $1 \mathrm{ps}$ duration and $18 \mathrm{pJ}$ of energy. The supermode suppression at the 322nd harmonic is better than $25 \mathrm{~dB}$. In addition, the transition dynamics from a bunched state of pulses to stable harmonic mode locking is presented, revealing a very long time scale. () 2009 Optical Society of America

OCIS codes: $140.3510,140.7090,060.5530$.

Short-pulse generation with rare-earth-doped fiber lasers has attracted much attention in the past few years [1-5]. This is related to the inherent properties of fibers that have allowed all-fiber, compact, and powerful passively mode-locked sources to be developed. Rare-earth doped fibers exhibit a large spectral gain bandwidth compatible with the generation of ultrashort pulses. Recently, the development of highrepetition rate fiber lasers in the gigahertz $(\mathrm{GHz})$ range and beyond has attracted particular attention. For that purpose, laser operation in the anomalous dispersion regime provides a quantization of pulse energy with moderate levels in the range of typically tens of picojoules. Under this condition, it is possible to generate several pulses per cavity round trip with moderate pumping levels [6]. Considering recent advances in watt-level pumping sources and all-fiber components, these basic properties are of major importance for the goal of achieving repetition rates exceeding the $\mathrm{GHz}$ range. In addition to the repetition rate, it is crucial to obtain a high suppression of supermodes together with a low timing jitter and low amplitude fluctuations. Until recently, the poor stability of harmonic mode locking (HML) obtained in fiber cavities led to considering two main options. One option is the reduction of the cavity round trip, since the lower the harmonic, the more stable the output repetition rate should be [7]. Forces arising from gain depletion and recovery can become efficient in stabilizing the stream of pulses [8]. The other option consists in actively mode locking the fiber cavity through the use of an rf-driven electro-optical modulator [9].

In the present Letter, we revisit the harmonic mode-locking scheme, showing that a fiber laser cavity of standard length, i.e., around $20 \mathrm{~m}$, can produce high HML with a relatively large supermode suppression, provided that the pumping power is large enough and that a fine setting of the intracavity mode locking wave plates is done. A previous experimental report highlighted the 91st harmonic (about $2 \mathrm{GHz}$ ) in a Yb-doped double-clad fiber laser with a supermode suppression of $25 \mathrm{~dB}$ [10]. An extensive characterization of harmonic passive mode locking was presented in [11] based on an Yb-doped soliton fiber laser. The 31st harmonic was obtained, corresponding to a repetition rate of about $1.5 \mathrm{GHz}$. The supermode suppression was very good, about $45 \mathrm{~dB}$, the timing jitter was between 5 and $10 \mathrm{ps}$, and the pulse duration was close to the Fourier-transform limit. In Er-doped fiber lasers, passive HML has also been obtained $[6,7,12]$ In [12], the repetition rate was scalable up to $1.2 \mathrm{GHz}$ (about the 140th harmonic) with a level of supermode suppression of $30 \mathrm{~dB}$.

In this Letter we report passive HML in an Erdoped double-clad fiber laser operating at $1.55 \mu \mathrm{m}$ in the soliton regime. The experimental setup is shown in Fig. 1. Mode locking is achieved through nonlinear polarization rotation technique. The laser cavity is a unidirectional ring with several fibers in series. We use a double-clad Er:Yb fiber amplifier manufactured by Keopsys. Two identical laser diodes operating at $980 \mathrm{~nm}$ and emitting about $3 \mathrm{~W}$ each are used in a counterpropagating geometry. The 8-m-long doubleclad fiber has a second-order dispersion $\beta_{2}=$ $-0.015 \mathrm{ps}^{2} / \mathrm{m}$. Pieces of standard fiber (SMF 28) and dispersion-shifted fiber are used to control the total dispersion of the cavity, which is $\beta_{2}^{\mathrm{TOT}} L=-0.04 \mathrm{ps}^{2}$. Nonlinear losses can be varied by a rotation of the intracavity phase plates. A $10 \%$ output coupler is used

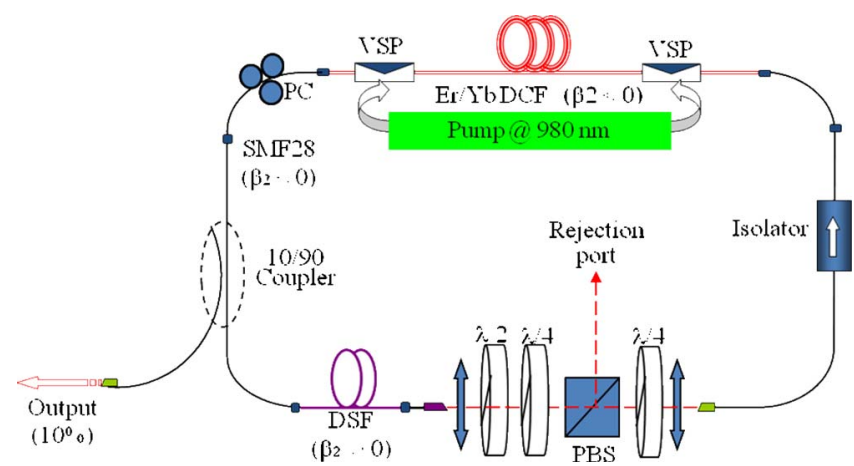

Fig. 1. (Color online) Experimental setup. VSP, v-groove side-pumping; DCF, double-clad fiber; DSF, dispersionshifted fiber; SMF, single-mode fiber; PBS, polarization beam splitter. 
to extract the power from the cavity. The output beam is detected with a high-speed photodiode (Newport TIA $120013 \mathrm{GHz}$ ) and analyzed with either a high-speed oscilloscope (Tektronix TDS 6124C $12 \mathrm{GHz}, 40 \mathrm{GS} / \mathrm{s}$ ) or an electronic spectrum analyzer (Rohde \& Schwarz FSP Spectrum Analyzer $9 \mathrm{kHz}-13.6 \mathrm{GHz}$ ). Pulse duration is measured with an optical autocorrelator (Femtochrome FR-103 XL) with a scanning range scalable to about $170 \mathrm{ps}$, and an optical spectrum analyzer (Anritsu MS 9710C) is also used.

With a pumping power above $2 \mathrm{~W}$, mode locking with several hundred pulses is readily achieved, but most of the corresponding regimes do not consist in regularly spaced pulses. Instead, grouping of pulses is frequently observed [4]. However, we have found particular sets of orientations for the intracavity wave plates that allow a transition from a large bunched state of pulses to high-harmonic-order mode locking. As was previously mentioned [6,13], the transition is particularly long, and we have recorded it as illustrated in Fig. 2, which presents the temporal distribution of the output intensity at different times. The results have been obtained for a total pumping power of $2.2 \mathrm{~W}$. At the beginning, the signal consists in an unresolved bunched state of several hundred pulses that fill about $10 \%$ of the cavity length [see Fig. 2(a)]. Gradually, the bunch spreads over a large part of the cavity as shown in Figs. $2(\mathrm{~b})-2(\mathrm{~d})$. This takes place in about $40 \mathrm{~s}$. After that, the evolution is slower, and it takes about $160 \mathrm{~s}$ for the pulses to fill the whole cavity as displayed in Fig. 2(e). The horizontal magnification of Fig. 2(e) [Fig. $2(\mathrm{f})]$ reveals that the pulse distribution is uniform. Thus the laser operates in a high-order HML regime. The final repetition rate is $3.079 \mathrm{GHz}$, which has to be compared with the fundamental cavity frequency $9.562 \mathrm{MHz}$, resulting in the generation of the $322 \mathrm{nd}$ harmonic, a record for this type of laser configuration to the best of our knowledge. The HML is self- starting in the sense that if the pump power is switched off and then switched on, the HML regime is restored and is stable over several hours when the external temperature does not vary. In the experiment, we have obtained even higher frequencies (about $5 \mathrm{GHz}$ ) but with a lower stability. Therefore we focus on the characterization on the $322 \mathrm{nd}$ harmonic order.

As previously discussed in the literature, HML quality is determined through different parameters [14]. The first one is the rate of suppression of supermodes $[10,11]$ that is deduced from the analysis of the $\mathrm{RF}$ spectrum of the output intensity, around the harmonic-repetition-rate frequency. Figure 3 clearly shows the repetition frequency of the laser and its harmonics and also additional peaks separated by the fundamental cavity frequency. The inset shows a magnification from which we can deduce the rate of supermode suppression, better than $25 \mathrm{~dB}$. This value is close to the one reported in the $\mathrm{Yb}$-doped fiber laser that operated at lower frequencies [10,11]. Other important characteristics are the amplitude fluctuations and the timing jitter. As discussed in [15], they can be quantified from rf power spectrum measurements. However, in HML lasers, the existence of supermodes makes this procedure very difficult to exploit as pointed out in [11]. An alternative method to measure the timing jitter is based on cross correlation $[8,11]$, which implies in our case an interferometric setup with a delay range above 300 ps, beyond the range of our optical correlator; so we could not measure the timing jitter with the available apparatus.

The other performances of the HML laser are as follows. The average output power is $54 \mathrm{~mW}$, leading to an output energy of $18 \mathrm{pJ}$ per pulse, a value slightly higher than the one reported in [11] for the Yb-doped fiber laser. Higher pulse energy can be expected in our experiment by simply increasing the output coupling. Figure 4 shows the autocorrelation

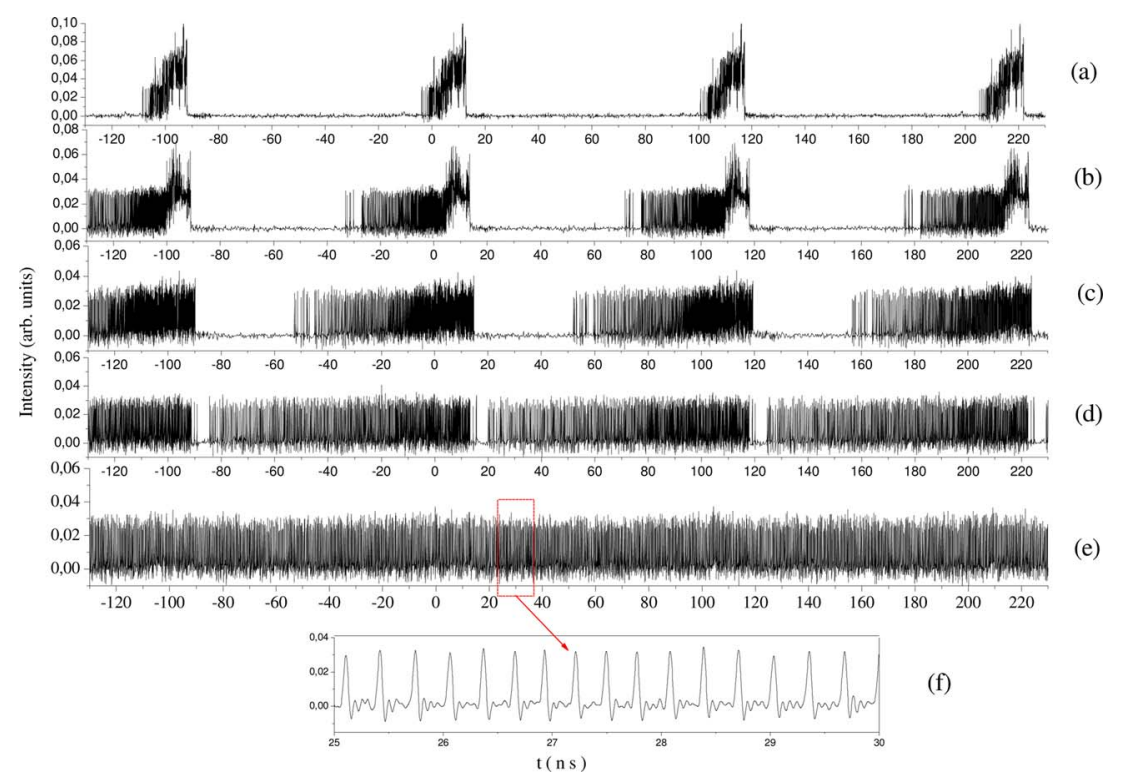

Fig. 2. (Color online) Temporal distribution of the output intensity at different recording times. (a) $t=0$, (d) $t=40 \mathrm{~s}$, and (e) $t=200 \mathrm{~s}$. (f) is an enlargement of (e). 


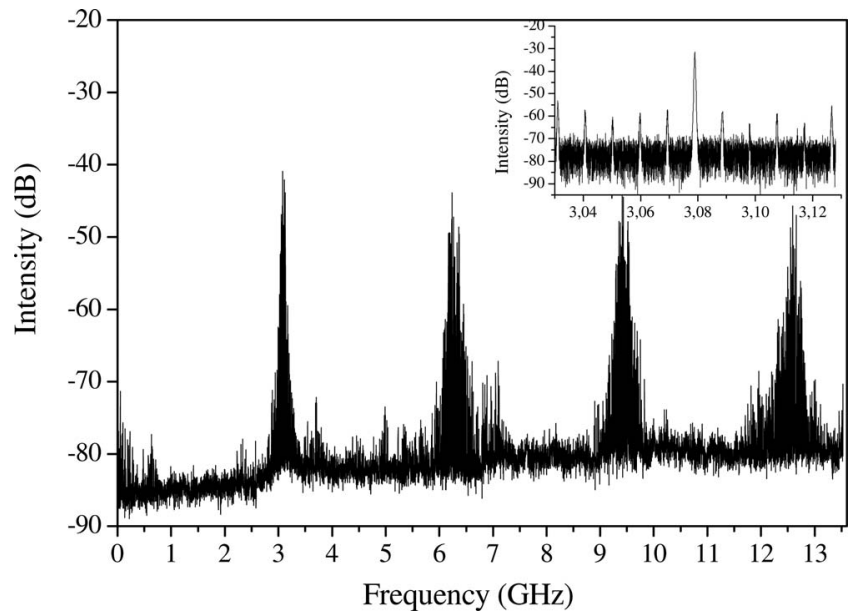

Fig. 3. RF spectrum of the output intensity in the range 0-13 GHz. Inset, enlargement around the repetition frequency of the cavity.

signal of the pulses around zero delay. A good fit is obtained by using a sech-pulse shape, yielding a pulse duration of $\Delta \tau \approx 1 \mathrm{ps}$. The optical spectrum is given in Fig. 5. The spectral bandwidth at half-maximum is $\Delta \lambda \approx 10 \mathrm{~nm}$. Thus the time-bandwidth product is $\Delta \tau \Delta \nu \approx 1.2$, about four times higher than the Fouriertransform limit. Such frequency chirping arises from the location of the output port after the single-mode fiber in the dispersion-managed cavity.

Inspection of the optical spectrum reveals additional physical insights into the formation mechanism of the harmonic mode-locked regime. Indeed, every HML regime is correlated in our setup with the existence of a cw component observable in the optical spectrum. Although several hypotheses have been put forward to explain the formation of the HML $[8,11,12]$, it seems that the interaction of pulses through a cw component is responsible for high-order HML [12]. In addition, we have recently theoretically demonstrated that a small cw component in the spectrum allows controlling the sign and the amplitude of the soliton interaction [16]. By a suitable choice of the laser parameters, one can achieve repulsion of intracavity ultrashort pulses. The repulsing force increases as the distance between pulses decreases. As result, after transient process, a passive HML regime

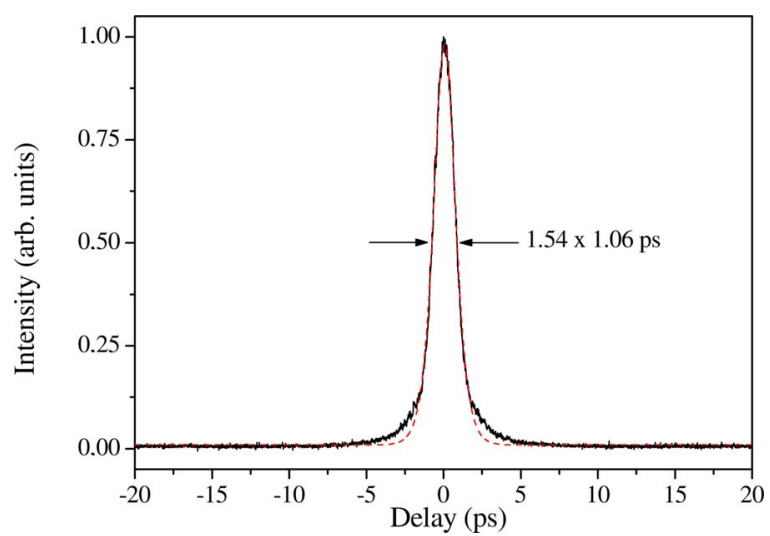

Fig. 4. (Color online) Autocorrelation trace and a sech fit (dashed curve).

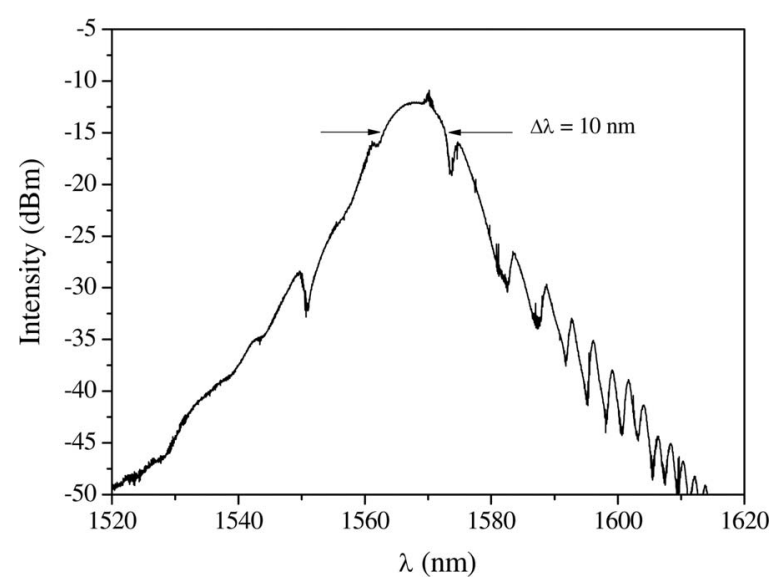

Fig. 5. Optical spectrum.

is established. Of course, in the experiment it is difficult to precisely control the frequency and the amplitude of an additional $\mathrm{cw}$ component through the adjustment of the phase plates, but the large number of degrees of freedom in the present type of modelocking allows the realization of stable passive HML.

In summary, we have demonstrated a high-order harmonic-mode-locked Er-doped double-clad fiber laser. The formation dynamics of such HML occurs on a very long time scale in comparison with other characteristic time scales of the laser. Finally, a strong correlation between the HML regime and the existence of a cw component has been pointed out, in agreement with previous theoretical predictions.

\section{References}

1. A. Hideur, T. Chartier, M. Brunel, S. Louis, C. Özkul, and F. Sanchez, Appl. Phys. Lett. 79, 3389 (2001).

2. F. Ö. Ilday, J. R. Buckley, H. Lim, F. Wise, and W. G. Clark, Opt. Lett. 28, 1365 (2003).

3. A. Komarov, H. Leblond, and F. Sanchez, Opt. Commun. 267, 162 (2006).

4. J. M. Soto-Crespo and $\mathrm{Ph}$. Grelu, in Dissipative Solitons, N. Akhmediev and A. Ankiewicz, eds., Vol. 661 of Lecture Notes in Physics (Springer, 2005), pp. 207-240.

5. B. Ortaç, A. Hideur, T. Chartier, M. Brunel, C. Özkul, and F. Sanchez, Opt. Lett. 28, 1305 (2003).

6. A. B. Grudinin and S. Gray, J. Opt. Soc. Am. B 14, 144 (1997).

7. B. C. Collings, K. Bergman, and W. H. Knox, Opt. Lett. 23, 123 (1998).

8. J. N. Kutz, B. C. Collings, K. Bergman, and W. H. Knox, IEEE J. Quantum Electron. 34, 1749 (1998).

9. T. F. Carruthers and I. N. Duling III, Opt. Lett. 21, 1927 (1996).

10. B. Ortaç, A. Hideur, G. Martel, and M. Brunel, Appl. Phys. B 81, 507 (2005).

11. S. Zhou, D. G. Ouzounov, and F. Wise, Opt. Lett. 31, 1041 (2006).

12. Z. X. Zhang, L. Zhan, X. X. Yang, S. Y. Luo, and Y. X. Xia, Laser Phys. Lett. 4, 592 (2007).

13. B. Ortaç, A. Hideur, and M. Brunel, Opt. Lett. 29, 1995 (2004).

14. F. Rana, H. L. T. Lee, R. J. Ram, M. E. Grein, L. A. Jiang, E. P. Ippen, and H. A. Haus, J. Opt. Soc. Am. B 19, 2609 (2002).

15. D. Von Der Lind, Appl. Phys. B B39, 201 (1986).

16. A. Komarov, K. Komarov, H. Leblond, and F. Sanchez, J. Opt. A 9, 1149 (2007). 